\title{
Fibroblast growth factor-20 increases the yield of midbrain dopaminergic neurons derived from human embryonic stem cells
}

\author{
Ana Sofia Correia*, Sergey V. Anisimova, Laurent Roybon, Jia-Yi Li and Patrik Brundin \\ Neuronal Survival Unit, Department of Experimental Medical Science, Lund University, Wallenberg Neuroscience Center, Lund, Sweden
}

Edited by: Javier DeFelipe, Cajal Institute (CSIC), Spain

Reviewed by: Brigitte Onteniente, Institut National De La Sante et Dd La Recherche Medicale, France

Jun Takahashi, Kyoto University, Japan

\begin{abstract}
In the central nervous system, fibroblast growth factor (FGF)-20 has been reported to act preferentially on midbrain dopaminergic neurons. It also promotes the dopaminergic differentiation of stem cells. We have analyzed the effects of FGF-20 on human embryonic stem cells (hESCs) differentiation into dopaminergic neurons. We induced neuronal differentiation of hESCs by co-culturing those with PA6 mouse stromal cells for 3 weeks. When we supplemented the culture medium with FGF-20, the number of tyrosine hydroxylase (TH)expressing neurons increased fivefold, from $3 \%$ to $15 \%$ of the hESC-derived cells. The cultured cells also expressed other midbrain dopaminergic markers (PITX3, En1, Msx1, and Aldh1), suggesting that some had differentiated into midbrain dopaminergic neurons. We observed no effect of FGF-20 on the size of the soma area or neurite length of the TH-immunopositive neurons. Regardless of whether FGF-20 had been added or not, $17 \%$ of the hESC-derived cells expressed the pan-neuronal marker b-III-Tubulin. The proportion of proliferating cells positive for Ki-67 was also not affected by FGF-20 (7\% of the hESC-derived cells). By contrast, after 3 weeks in culture FGF-20 significantly reduced the proportion of cells undergoing cell death, as revealed by immunoreactivity for cleaved caspase-8, Bcl-2 associated X protein (BAX) and cleaved caspase-3 (2.5\% to $1.2 \%$ of cleaved caspase-3-positive cells out of the hESC-derived cells). Taken together, our results indicate that FGF-20 specifically increases the yield of dopaminergic neurons from hESCs grown on PA6 feeder cells and at least part of this effect is due to a reduction in cell death.
\end{abstract}

Keywords: human embryonic stem cells, fibroblast growth factor-20, dopaminergic neurons, differentiation, Parkinson's disease, stem cell therapy, apoptosis, caspase-3

\section{INTRODUCTION}

Parkinson's disease is a progressive neurodegenerative disorder, characterized by tremor, muscle rigidity, and bradykinesia, which primarily is due to the degeneration of dopaminergic neurons in the substantia nigra (Braak et al., 2004). Replacement of the lost dopaminergic neurons by transplantation has been tested, with varying degrees of success, as a therapy for Parkinson's disease (Bjorklund et al., 2003). These trials have used ventral mesencephalic donor tissue obtained from routine abortions. However, the usage of this source of donor tissue is associated with several problems. For example, it is not readily obtainable; its developmental stage varies; it is heterogeneous in cell composition; it differs in

\footnotetext{
* Correspondence: Ana Sofia Correia, Neuronal Survival Unit, Department of Experimental Medical Science, Lund University, Wallenberg Neuroscience Center, BMC A10, 22184 Lund, Sweden. Tel: +46 46 2220524, Fax: +46 462220531. e-mail: sofia.correia@med.lu.se

${ }^{a}$ Currently at: V.A. Almazov Federal Center for Heart, Blood and Endocrinology, SaintPetersburg, 197341, Russia \& Cureline, Inc., San Francisco, CA 94080, USA.

Received: 30 0ct. 2007; paper pending published: 7 Dec. 2007; accepted: 12 Dec. 2007; Published online: 30 Dec. 2007

Full citation: Frontiers in Neuroanatomy (2007) 1:4 doi: 10.3389/neuro.05/004.2007 Copyright (C) 2007 Correia, Anisimov, Roybon, Li and Brundin. This is an open-access article subject to an exclusive license agreement between the authors and the Frontiers Research Foundation, which permits unrestricted use, distribution, and reproduction in any medium, provided the original authors and source are credited.
}

quality due to different post-mortem delays and handling procedures; and it is inherently connected to ethical issues related to the abortion (Freeman, 2006). An ideal source of cell material should be obtainable in large quantities in a predictable manner, highly enriched in midbrain dopaminergic neurons of a substantia nigra phenotype, and safe to transplant with no risks of infection or tumor growth (Takahashi, 2007). Embryonic stem cells (ESCs), derived from the inner cell mass of human blastocysts, are such a potential source of cells. They are pluripotent, can self-renew and it is possible to derive dopaminergic neurons from human ESCs ( $\mathrm{hESCs}$ ) by using various cell culture protocols. Specific types of feeder cells and combinations of signaling molecules have been shown to induce the differentiation of hESCs into dopaminergic neurons (Ben-Hur et al., 2004; lacovitti et al., 2007; Perrier et al., 2004; Roy et al., 2006; Schulz et al., 2004; Zeng et al., 2004). So far, the highest proportion of neurons expressing the dopamine-synthesizing enzyme tyrosine hydroxylase (TH) obtained from hESCs is $65-78 \%$ (Perrier et al., 2004).

We were interested in studying the effects of a growth factor previously not tested in this context, on its ability to further promote the number of dopaminergic neurons obtained from hESCs. Fibroblast growth factor (FGF)-20 and its receptor are expressed in the substantia nigra and FGF20 has a preferential neurotrophic activity, including a survival-promoting effect, on dopaminergic neurons (Murase and McKay, 2006; Ohmachi et al., 2000; Ohmachi et al., 2003). This factor also promotes the differentiation of certain types of stem cells into dopaminergic neurons in vitro (Grothe et al., 2004; Takagi et al., 2005). Based on these properties of FGF-20, we hypothesized that FGF-20 would increase the yield of 
dopaminergic neurons derived from hESCs. We supplemented cultures of hESCs, during differentiation on PA6 stromal feeder cells (Kawasaki et al., 2000), with FGF-20. We report that FGF-20 supports a fivefold increase in the percentage of hESC-derived TH-expressing neurons and reduces cell death during differentiation. Our study provides novel information of importance to cell-replacement therapy for Parkinson's disease based on dopaminergic neurons derived from hESCs.

\section{MATERIALS AND METHODS}

SDIA method for in vitro differentiation of hESCs into DA neurons We maintained undifferentiated hESCs (SA002 cell line, Cellartis, Göteborg, Sweden) on irradiated human foreskin fibroblasts (hFFs, CRL-2429, ATCC, Manassas, VA; feeder cell density 36,000-45,000 cells/ $\mathrm{cm}^{2}$ ) using medium containing serum replacement (VitroHES medium, Vitrolife Sweden AB, Sweden), supplemented with $4 \mathrm{ng} / \mathrm{ml}$ of basic fibroblast growth factor (human recombinant bFGF, also known as FGF-2, Invitrogen, CA). Every 6-7 days, we cut hESC colonies into small cell clusters, and used glass stem cell knives (SweMed AB, Sweden) to mechanically separate them from hFFs. We then placed the clusters of hESCs on top of fresh hFFs for expansion, or on top of PA6 mouse bone marrow stromal cell feeders for differentiation. Details regarding the protocol for culturing PA6 cells have been described previously (Kawasaki et al., 2000). For immunocytochemical analysis of differentiated cells, we plated PA6 cells on collagen-coated glass coverslips in 4-well-plates at the density of 20,000-25,000 cells $/ \mathrm{cm}^{2} 2$ days prior to co-culturing with hESCs. For RT-PCR analysis, we co-cultured hESCs and PA6 cells on gelatine-coated plastic $35 \mathrm{~mm}$ Petri dishes. Before starting the hESC/PA6 co-cultures, we rinsed the PA6 cell three times with phosphate buffered saline (PBS) to remove the traces of serum-containing PA6 culture medium. We maintained the co-cultures in medium composed of Glasgow's modified Eagle's medium (G-MEM) supplemented with $8 \%$ knockout serum replacement (KO-SR), $2 \mathrm{mM}$ L-glutamine, $0.1 \mathrm{mM}$ nonessential amino acids (NEAA), $1 \mathrm{mM}$ pyruvate, $0.1 \mathrm{mM}$ 2-mercaptoethanol (2-ME), and $4 \mathrm{ng} / \mathrm{ml}$ bFGF (all from Invitrogen). In hESC differentiation studies, FGF-20 (PeproTech EC, UK) was added in a concentration of $1 \mathrm{ng} / \mathrm{ml}$. Based on the results of pilot experiments in which we tested three concentrations of FGF-20 (100 pg/ml, $1 \mathrm{ng} / \mathrm{ml}$, and $10 \mathrm{ng} / \mathrm{ml})$, we chose to treat our cultures with $1 \mathrm{ng} / \mathrm{ml}$ FGF-20. For first 10 days of co-culturing, we changed one half of the medium volume every other day, followed by daily changes until a total of 21 days.

\section{Immunocytochemistry}

Following 3 weeks of culturing, we fixed the hESC/PA6 co-cultures with $4 \%$ paraformaldehyde (PFA) for 30 minutes. We pre-incubated the fixed cells in blocking solution containing PBS, $0.5 \%$ Triton X-100, and $10 \%$ of normal serum from the same animal species as the secondary antibody. We then incubated cultures with primary antibodies in blocking solution overnight at room temperature. Following three washes with PBS, we incubated cells with donkey anti-mouse IgG conjugated with FITC, Cy2, or Cy3 (1:200, Jackson ImmunoResearch Europe Ltd., UK). Subsequently, we washed cells with PBS and incubated them with 1:1000 4',6diamidino-2-phenylindole (DAPI) in PBS for 10 minutes. Using PVA mounting medium containing anti-fading reagent $D A B C O$ we mounted the glass coverslips onto glass slides. The primary antibodies that we used were the following: mouse monoclonal anti-human nuclei (HNuc, 1:200); rabbit polyclonal anti-TH (1:500); rabbit polyclonal anti-vesicular monoamine transporter (VMAT)-2 (1:500, all from Chemicon, CA); mouse monoclonal anti-Nestin (1:50); goat polyclonal anti-PITX3 (1:50, both from Santa Cruz Biotechnology, Inc., CA); rabbit polyclonal anti-b-III-Tubulin (1:500, Nordic BioSite AB, Sweden); rabbit monoclonal anti-cleaved caspase-3 (1:100); rabbit polyclonal cleaved caspase-8 (1:100), rabbit polyclonal $\mathrm{Bcl}-2$ associated $\mathrm{X}$ protein (BAX, 1:100, all from Cell Signalling Technology, MA); rabbit polyclonal anti-Ki67 (1:200, Novocastra
Laboratories, UK); mouse monoclonal anti-FGF receptor 1 (FGFR-1, 1:80, Zymed Laboratories Inc., CA).

\section{Cell counting, neurite outgrowth estimation, soma area measurements, and statistical analysis}

We quantified the percentages of TH-, b-III-Tubulin-, Ki67-, and cleaved caspase-3-positive cells from four independent experiments. We applied stereological principles to assess cell numbers using the Visiopharm Integrator System version 2.12.1.0 software. After delineating the culture areas covered with HNuc-positive cells, we assessed the numbers of immunopositive cells using a systematic random sampling technique. We analyzed about 1000 cells in each culture. Using the StatView 5.0 software we performed the statistical evaluation by student's $t$-test for two unpaired groups. Cell fraction data were presented as means \pm SEM. We estimated the neurite length per cell by counting the number of intersections of neuritis and six probe lines equally spaced in the counting frame drawn by the Visiopharm Integrator System program. We analyzed at least 100 neurons per culture of three independent experiments (totaling 300 cells per culture condition) and presented the data as means $\pm S D$. This method is an adaptation of the procedure developed by Ronn et al., (2000). For the estimation of soma area we randomly chose 20 cells per culture of three independent experiments (totaling 80 cells per culture condition) and measured the soma area of each cells again using the Visiopharm Integrator System program. Soma area data were presented as means \pm SD.

\section{RNA purification and CDNA synthesis}

For RNA purification of undifferentiated hESCs, we mechanically separated the hESCs from hFFs, collected the former in a $500 \mu \mathrm{l}$ volume of VitroHES media, rinsed in PBS buffer and spun down at 300 rcf for 5 minutes. To harvest hESC-derived cells grown atop PA6 cells (in the presence or absence of FGF-20) we used the papain dissociation kit (Worthington Biochemical Corporation, NJ), rinsed cells in PBS buffer and spun down as described above. We then resuspended the resulting cell pellets in RLT buffer (QIAGEN, UK), passed through the shredder column (QIAGEN) and stored at $-80^{\circ} \mathrm{C}$ until the RNA sample was purified following the RNeasy Micro Kit (QIAGEN) protocol (without carrier RNA); with DNase I (QIAGEN) treatment incorporated to the latter. Using a ND-1000 specrophotometer (NanoDrop, USA) we tested the RNA integrity. Later we synthesized cDNA from $400 \mathrm{ng}$ of total RNA using SuperScript II (Invitrogen), essentially as recommended by the manufacturer, with extended synthesis step (50 minutes).

\section{RT-PCR}

We selected the primers for RT-PCR from published works (Hori et al., 2005; Jorgensen et al., 2006; Kukekov et al., 1999; Yu et al., 2006) or designed those using Oligo 4.0 software (Molecular Biology Insight) or Clone Manager Suite 7.1 (Sci Ed Software, NC), as appear at Table 1. We ordered all primers from TAG Copenhagen A/S, Denmark. Using the MiniOpticon system (Bio-Rad, USA) with REDTaq Polymerase (SigmaAldrich, Germany) we performed the RT-PCR amplifications, essentially as described by the manufacturer. Following initial denaturation for 5 minutes at $95^{\circ} \mathrm{C}$, we performed DNA amplifications for 32 (Aldh1a1), 33 (Hprt, Th, Msx1) or 35 (En1) cycles of 1 minutes at $95^{\circ} \mathrm{C}, 1$ minutes at $55^{\circ} \mathrm{C}$ (En1), $58.5^{\circ} \mathrm{C}$ (Th) or $59^{\circ} \mathrm{C}$ (Aldh1a1, Hprt, Msx1), and 1 minutes at $72^{\circ} \mathrm{C}$. The final extension was 5 minutes at $72^{\circ} \mathrm{C}$. We analyzed $20 \mu \mathrm{l}$ volumes of RT-PCR products by electrophoresis at $1 \%$ Agarose gels and visualized by Ethidium Bromide staining.

\section{RESULTS}

\section{FGF-20 promotes the differentiation of hESCs into midbrain dopaminergic neurons}

We maintained the hESC colonies on hFFs (Figure 1A). In order to induce the differentiation of $\mathrm{hESCs}$ into dopaminergic neurons, we isolated 
Table 1. List of primers used in this study.

\begin{tabular}{|c|c|c|c|c|}
\hline Gene name & Abbreviation & Primers & Orientation & Product size (bp) \\
\hline Tubulin beta & Tubb & $\begin{array}{l}\text { 5'-CTCACAAGTACGTGCCTCGAG-3' } \\
5^{\prime} \text {-GCACGACGCTGAAGGTGTTCA-3' }\end{array}$ & $\begin{array}{l}\text { Sense } \\
\text { Anti-sense }\end{array}$ & 593 \\
\hline Hypoxanthine guanine phosphoribosyltransferase 1 & Hprt & $\begin{array}{l}\text { 5'-TGTAATGACCAGTCAACAGGG-3' } \\
5^{\prime} \text {-TGGCTTATATCCAACACTTCG-3' }\end{array}$ & $\begin{array}{l}\text { Sense } \\
\text { Anti-sense }\end{array}$ & 816 \\
\hline Glyceraldehyde-3-phosphate dehydrogenase & Gapdh & $\begin{array}{l}\text { 5'-TTAGCACCCCTGGCCAAGG-3' } \\
\text { 5'-CTTACTCCTTGGAGGCCATG-3' }\end{array}$ & $\begin{array}{l}\text { Sense } \\
\text { Anti-sense }\end{array}$ & 452 \\
\hline Octamer-binding transcription factor $3 / 4$ & $0 \mathrm{ct} 3 / 4$ & $\begin{array}{l}\text { 5'-CTTGCTGCAGAAGTGGGTGGAGGA-3' } \\
5^{\prime} \text {-CTGCAGTGTGGGTTTCGGGCA-3' }\end{array}$ & $\begin{array}{l}\text { Sense } \\
\text { Anti-sense }\end{array}$ & 360 \\
\hline Homeobox transcription factor Nanog & Nanog & $\begin{array}{l}\text { 5'-TGCTTATTCAGGACAGCCT-3' } \\
5^{\prime} \text {-TCTGGTCTTCTGTTTCTTGACT-3' }\end{array}$ & $\begin{array}{l}\text { Sense } \\
\text { Anti-sense }\end{array}$ & 538 \\
\hline Aldehyde dehydrogenase 1 family, member A1 & Aldh1 & $\begin{array}{l}\text { 5'-GGGCAGCCATTTCTTCTCAC-3' } \\
5^{\prime} \text {-CTTCTTAGCCCGCTCAACAC-3' }\end{array}$ & $\begin{array}{l}\text { Sense } \\
\text { Anti-sense }\end{array}$ & 1181 \\
\hline Homeobox transcription factor msx-like 1 & Msx1 & $\begin{array}{l}\text { 5'-CGAGCTGTGAAGGTGTTTG-3' } \\
5^{\prime} \text {-TTGGTGACCAGGTGATGAC-3' }\end{array}$ & $\begin{array}{l}\text { Sense } \\
\text { Anti-sense }\end{array}$ & 332 \\
\hline Tyrosine hydroxylase & Th & $\begin{array}{l}\text { 5'-CGAGCTGTGAAGGTGTTTG-3' } \\
5^{\prime} \text {-TTGGTGACCAGGTGATGAC-3' }\end{array}$ & $\begin{array}{l}\text { Sense } \\
\text { Anti-sense }\end{array}$ & 245 \\
\hline Engrailed 1 & En1 & $\begin{array}{l}\text { 5'-AAGGGACGAAACTGCGAACTCC-3' } \\
5^{\prime} \text {-GACACGAAAGGAAACACACACTCTCG-3' }\end{array}$ & $\begin{array}{l}\text { Sense } \\
\text { Anti-sense }\end{array}$ & 245 \\
\hline
\end{tabular}

fragments of the hESC colonies from the hFFs and placed them on top of PA6 mouse stromal cells (Figure 1B). We confirmed the neuronal differentiation of the hESCs by the expression of the early neuronal marker Nestin in a large proportion of the cells (Figures 1C-1F). This observation is in good agreement with the known capacity of PA6 cells to induce neuronal differentiation in ESCs (Brederlau et al., 2006; Kawasaki et al., 2000; Morizane et al., 2002; Takagi et al., 2005).

The activity of FGF-20 is mediated by the FGFR-1 (Ohmachi et al., 2003). We detected this receptor on undifferentiated hESCs (Figures 1G-1I), PA6 cells (Figures 1J-1L), and hESC-derived TH-positive neurons (Figures 1M-10). Therefore FGF-20 might act directly on hESCs and on differentiated TH-expressing neurons. FGF-20 might also stimulate the PA6 cells to release factors that promote the dopaminergic differentiation and the survival of the derived dopaminergic neurons.

In addition to having a neurotrophic activity on rat midbrain dopaminergic neurons (Ohmachi et al., 2000), FGF-20 also increases the numbers of TH-expressing neurons derived from stem cells in vitro (Grothe et al., 2004; Takagi et al., 2005). When we treated hESC/PA6 cocultures with FGF-20 we observed a fivefold increase in the yield of THpositive cells (Figures 2A-2C). The percentage of TH-positive neurons out of HNuc-positive cells was $3 \pm 1 \%$ in the absence of FGF-20 (-FGF-20), while it increased to $15 \pm 2 \%$ in the presence of FGF-20 (+FGF-20) (Figure 2C). The TH-positive neurons co-expressed the vesicular monoamine transporter (VMAT)-2 (Figures 2D and 2E), which is involved in the vesicular transport of dopamine (Nirenberg et al., 1996). The hESCderived TH-positive neurons also co-expressed the paired-like homeodomain transcription factor 3 (PITX3, Figures $2 \mathrm{~F}$ and $2 \mathrm{G}$ ), required for the development of substantia nigra dopaminergic neurons (Nunes et al., 2003). We detected the homeobox transciption factor engrailed 1 (En1), which is essential for the maintenance of substantia nigra dopaminergic neurons (Alberi et al., 2004), by RT-PCR (Figure 2H). Using RT-PCR, we also detected expression of the homeobox transcription factor msh-like 1 (Msx1) (Andersson et al., 2006) and the enzyme aldehyde dehydrogenase 1 (Aldh1) (Galter et al., 2003), which are also involved in the development of midbrain dopaminergic neurons (Figure $2 \mathrm{H}$ ). Furthermore, we found lower expression levels of two markers of undifferentiated and pluripotent cells, that is, 0ct3/4 and Nanog, in differentiated hESC/PA6 co-cultures supplemented with FGF-20 than in cultures untreated with FGF-20, indicating the effect of this factor in promoting differentiation (Figure $2 \mathrm{H}$ ).

Other neurotrophic factors, such as glial cell line-derived neurotrophic factor (GDNF), neurotrophins (NTs), and transforming growth factor
(TGF)- $\alpha$ are known to increase the neurite length and soma area of mesencephalic neurons in culture (Alexi and Hefti, 1993; Studer et al., 1995; Studer et al., 1996; Widmer et al., 2000). We evaluated the effect of FGF-20 on neurite outgrowth of hESC-derived TH-positive neurons by quantifying the number of intersections between the neurites of each cell with six probe lines, equally spaced and drawn on the counting frame, as described by Ronn et al., (2000). We observed no increase in neurite length in cultures treated with FGF-20 (Figure 2l). Similarly, we observed no effect of FGF-20 treatment in the soma area of hESC-derived THpositive neurons (Figure 2J). These results suggest that FGF-20 has no significant effect on hESC-derived TH-positive neuron morphology.

\section{FGF-20 has no effect in the neuronal differentiation of hESCs}

The neurotrophic activity of FGF-20 is considered to be specific for THexpressing neurons in primary cultures of rat mesencephalic neurons (Ohmachi et al., 2003). FGF-20 increases the survival of TH-expressing neurons in serum-free medium, but it does not support a general survivalpromoting effect on all other neurons (Ohmachi et al., 2003). In our hESC/ PA6 co-cultures, FGF-20 did not increase the fraction of hESC-derived cells expressing the neuronal marker b-III-Tubulin (Figures 3A and 3B). The percentage of the HNuc-positive cells that expressed b-III-Tubulin was $18 \pm 1 \%$ and $16 \pm 2 \%$ in the FGF-20 treated and untreated cultures, respectively (Figure 3C). As expected, all the TH-positive neurons coexpress b-III-Tubulin (Figures 3D and 3E). Therefore, we can speculate that the percentage of $b$-III-Tubulin-positive cells co-expressing TH was about $85 \%$ in FGF-20-supplemented cultures, and $19 \%$ in the cultures lacking FGF-20 $(N=4)$. Taken together, these data suggest that FGF-20 may promote specifically the differentiation of hESCs into dopaminergic neurons, but not general neuronal differentiation.

\section{FGF-20 significantly reduces cell death through apoptosis but has no effect on cell proliferation}

Anti-apoptotic mechanisms have been shown to be activated by FGF-20 on dopaminergic neurons (Murase and McKay, 2006). We examined whether FGF-20 reduced apoptotic cell death in hESC/PA6 co-cultures. We identified dying cells by the presence of cleaved caspase-8, cleaved caspase-3, and oligomerized BAX (Figures 4A-4F). Activation of caspase8 into cleaved active fragments is induced by signaling through the FasL/ Fas receptor, as part of the extrinsic cell death pathway. It triggers the activation of a cascade of downstream caspases (Riedl and Shi, 2004). 

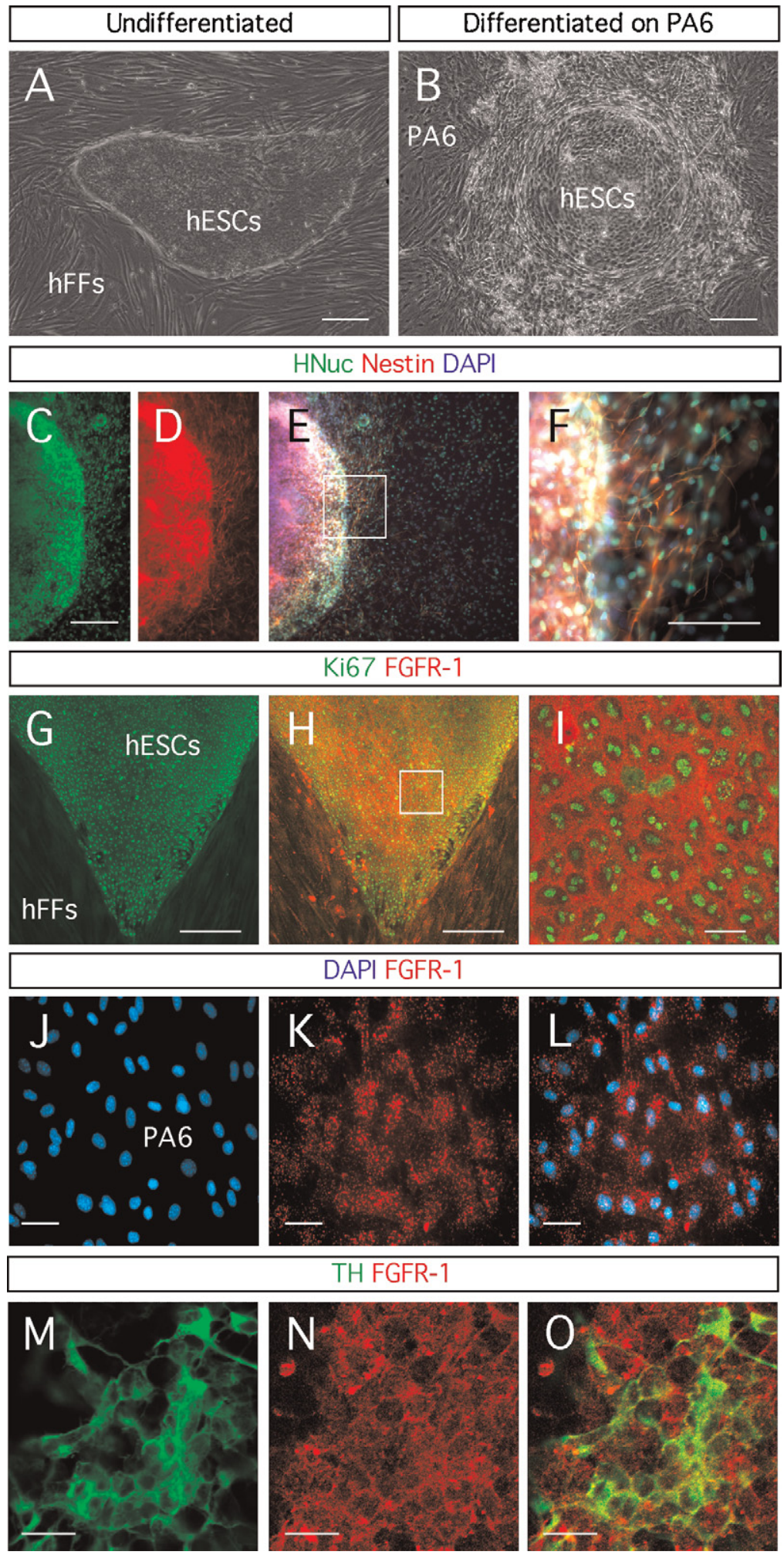

Figure 1. Neuronal differentiation of hESCs through the SDIA method. (A) Human embryonic stem cells (hESCs) growing on human foreskin fibroblasts (hFFs). (B) Differentiated hESCS on PA6 cells. (C-F) Expression of the early neuronal marker Nestin by the hESC-derived cells, identified by the expression of HNuc, after differentiation for 3 weeks on PA6 cells. Detection of fibroblast growth factor receptor (FGFR)-1 in: (G-I) hESCs identified by the expression of the proliferation marker Ki67; (J-L) a monolayer of PA6 cells; and (M-0) hESC-derived TH-expressing neurons. Distance bars: A-E, G, H: $200 \mu \mathrm{m} ; \mathrm{F}: 100 \mu \mathrm{m} ; \mathrm{I}, \mathrm{M}-0: 20 \mu \mathrm{m} ; \mathrm{J}-\mathrm{L}$ : $50 \mu \mathrm{m}$.

Cleaved caspase- 8 also induces the release of cytrochrome $c$ from the mitochondria as part of the intrinsic cell death pathway, mediated by proapoptotic proteins such as BAX (Riedl and Shi, 2004). Both the extrinsic and intrinsic pathways result in the activation of caspase- 3 , which then catalyzes the proteolysis of many proteins leading to the cell death (Riedl and Shi, 2004). In cultures untreated with FGF-20, we saw a significant number of hESC-derived cells positive for cleaved caspase-8 (Figure 4A) and BAX (Figure 4B). In contrast, we identified almost no cells double 

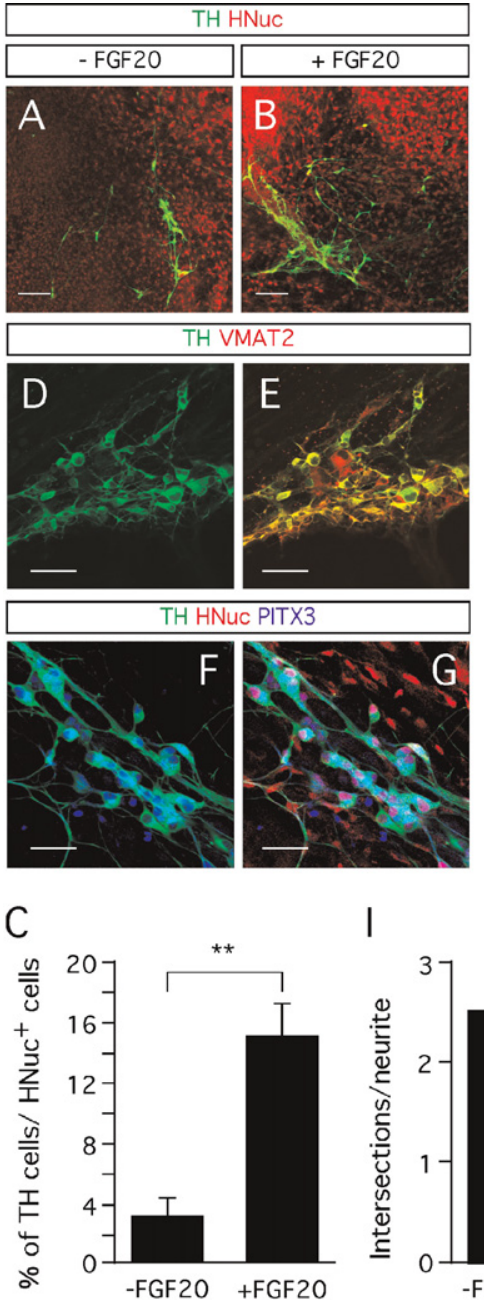$$
\text { । }
$$
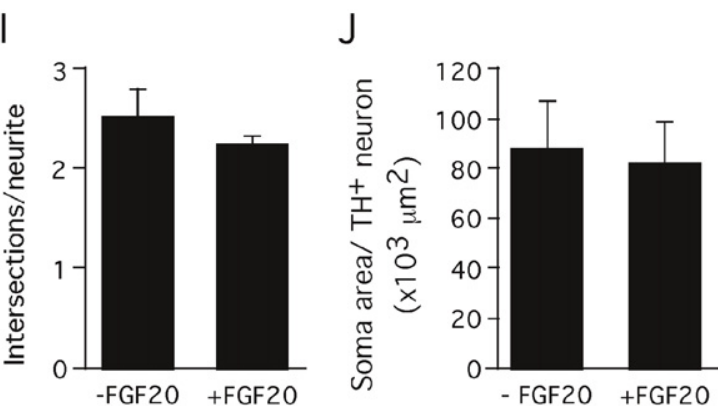

Figure 2. Effect of FGF-20 on dopaminergic differentiation. (A,B) Representative images of TH- and HNuc-positive cells in 3 weeks differentiated hESCs/PA6 co-cultures untreated (A) and treated (B) with FGF-20 (-FGF-20 and +FGF-20, respectively). (C) Graphic representation of the percentages of TH-positive cells among HNuc-positive cells in 3 weeks differentiated hESCs/PA6 co-cultures-FGF-20 and +FGF-20. Average \pm SEM. Student's t-test, $p$-value: ${ }^{* *}=0.0012$. (D,E) Co-expression of TH and the vesicular monoamine transporter (VMAT) 2. (F,G) Co-expression of TH and the paired-like homeodomain transcription factor 3 (PITX3). (H) RT-PCR analysis of gene expression on undifferentiated hESCs (undiff hESC line); PA6 mouse stromal cells (PA6 line); 3 weeks differentiated hESCs/ PA6 co-cultures without FGF-20 (-FGF-20 lines) and with FGF-20 (+FGF-20 lines). Undiff hESCs, undifferentiated human embryonic stem cells; - RT, no polymerase negative control. The three lines falling into both -FGF-20 and +FGF-20 conditions represent the RT-PCR analysis of three separate cultures maintained in the condition indicated. (I) Estimation of the TH-positive neurites length by the number of intersections of the neurites with probe lines in 3 weeks differentiated hESCS/PA6 co-cultures -FGF-20 and +FGF-20. Average \pm SD. (J) Soma area of TH-positive neurons in 3 weeks differentiated hESCs/PA6 cocultures - FGF-20 and +FGF-20. Average \pm SD. Distance bars: A, B: $200 \mu \mathrm{m} ; \mathrm{D}-\mathrm{G}: 50 \mu \mathrm{m}$.

positive for HNuc/cleaved caspase-8 (Figure 4D) and HNuc/BAX (Figure 4E) in cultures treated with FGF-20. This indicates that FGF20 inhibits apoptotic cell death that is mediated both via the intrinsic and the extrinsic pathways. Addition of FGF-20 resulted in reduction in the fraction of cells stained positive for cleaved caspase-3 $(1.2 \pm 0.5 \%)$ compared with cultures not supplemented with FGF-20 (2.5 $\pm 0.2 \%$, Figures 4C, 4F, and 4I). Previous studies have suggested that dying cells might downregulate the TH expression, limiting the possibility to identify dying TH-positive neurons (Burke, 2004). It might be for this reason that we did not find cells co-expressing TH and cleaved caspase-3 (Figures 4G and $4 \mathrm{H}$ ). However, we believe that the reduction in cell death results from a higher survival of dopaminergic neurons in the cultures due to the known preferential trophic activity of FGF-20 on these neurons (Murase and McKay, 2006; Ohmachi et al., 2000; Ohmachi et al., 2003).

Furthermore, we evaluated the effect of FGF-20 on cell proliferation. We identified proliferating cells by the expression of Ki67 (Figures 5A and 5B). Cultures untreated with FGF-20 contained $7 \pm 2 \%$ of Ki67- positive cells, among the HNuc-positive cells (Figure 5C). Similarly, those supplemented with FGF-20, Ki67-positive cells constituted $8 \pm 1 \%$ of the total number of cells (Figure $5 \mathrm{C}$ ). These data suggest that FGF-20 has no effect on cell proliferation in this culture paradigm.

\section{DISCUSSION}

Midbrain dopaminergic neurons can be generated from hESCs in vitro using several different culture protocols (Ben-Hur et al., 2004; lacovitti et al., 2007; Park et al., 2004; Park et al., 2005; Perrier et al., 2004; Roy et al., 2006; Schulz et al., 2004; Yan et al., 2005; Zeng et al., 2004). We show for the first time that FGF-20 can be used to increase fivefold the yield of TH-expressing neurons derived from hESCs (Figures 2A-2C), probably by promoting their differentiation and decreasing apoptotic cell death. Specifically, FGF-20 treatment reduced the fraction of cells that were immunoreactive for activated caspase-3, cleaved caspase-8, and BAX (Figures 4A-4F). The percentage of cleaved caspase-3-positive cells 


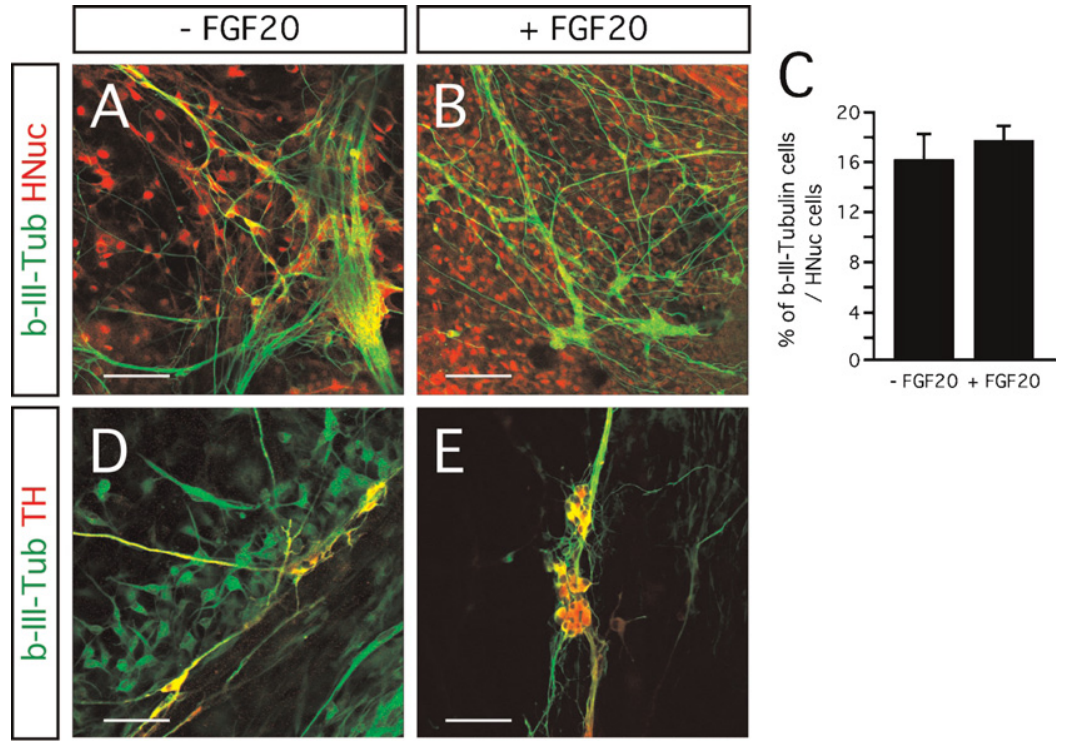

Figure 3. Effect of FGF-20 on neuronal differentiation. (A,B) Representative images of b-III-Tubulin- and HNuc-positive cells in 3 weeks differentiated hESCs/ PA6 co-cultures - FGF-20 (A) and +FGF-20 (B). (C) Graphic representation of the percentages of b-III-Tubulin-positive cells among HNuc-positive cells in 3 weeks differentiated hESCS/PA6 co-cultures - FGF-20 and +FGF-20. Average \pm SEM. (D,E) Co-Iocalization of b-III-Tubulin and TH in 3 weeks differentiated hESCs/PA6 co-cultures -FGF-20 (D) and +FGF-20 (E). Distance bars: A, B, D, E: $100 \mu \mathrm{m}$.

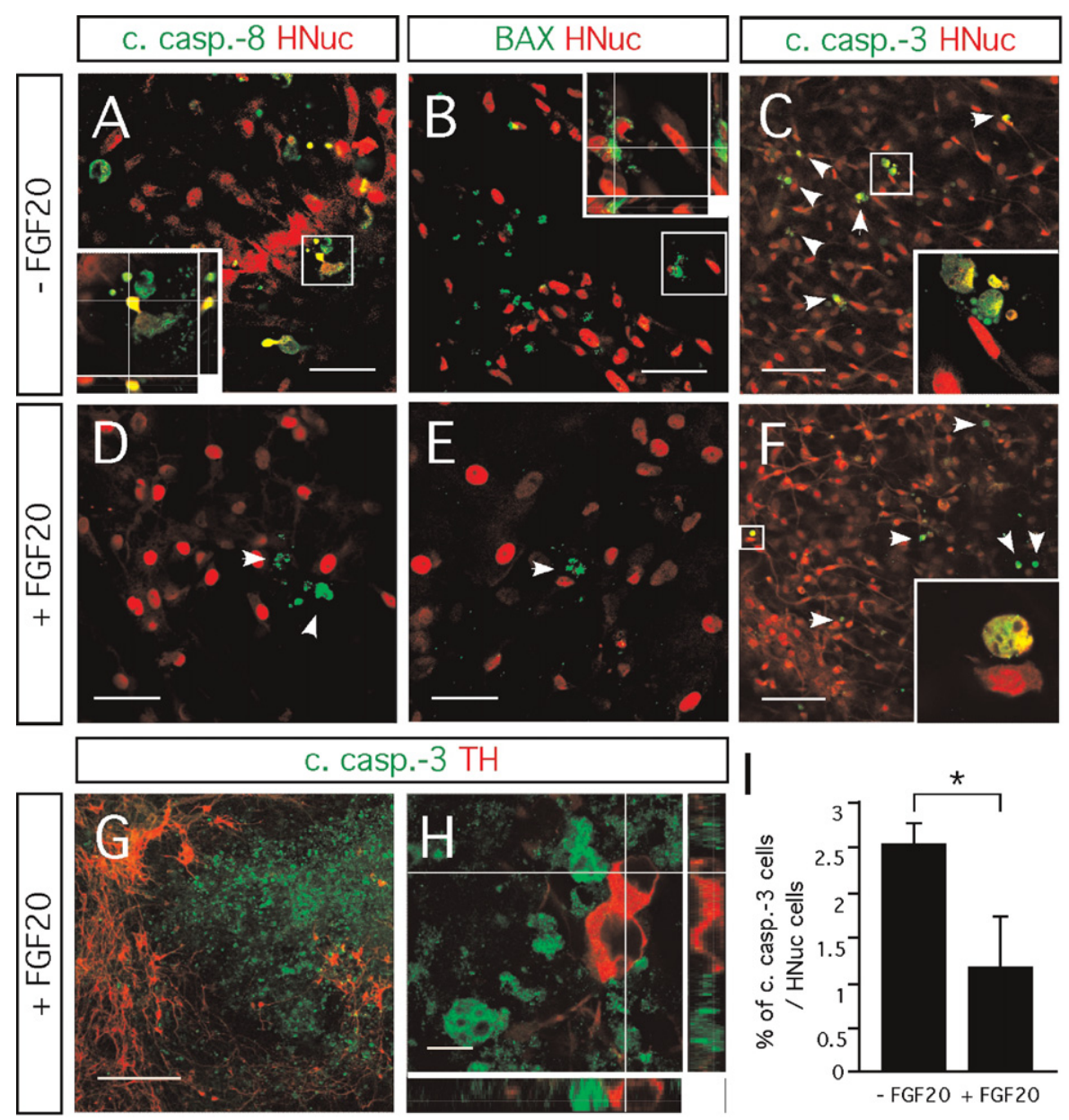

Figure 4. Effect FGF-20 on cell death. Representative images of 3 weeks differentiated hESCs/PA6 co-cultures untreated and treated with FGF-20 (-FGF-20 and + FGF-20, respectively) double-stained for (A,D) HNuc and cleaved caspase-8 (B,E), HNuc and BAX (C,F) HNuc and cleaved caspase-3 (arrowheads point on apoptotic cells), and $(\mathbf{G}, \boldsymbol{H})$ TH and cleaved caspase-3. (I) Graphic representation of the percentages of cleaved caspase-3-positive cells among HNuc-positive cells in 3 weeks differentiated hESCS/PA6 co-cultures - FGF-20 and + FGF-20. Average \pm SEM. Student's t-test, $p$-value: * $=0.05$. (G, H) Images showing cells positive for cleaved caspase-3 and TH in 3 weeks differentiated hESCs/PA6 co-cultures +FGF-20. Distance bars: A, B, D, E: $50 \mu \mathrm{m} ; \mathrm{C}, \mathrm{F}: 100 \mu \mathrm{m} ; \mathrm{G}: 200 \mu \mathrm{m} ; \mathrm{H}$ : $10 \mu \mathrm{m}$. 


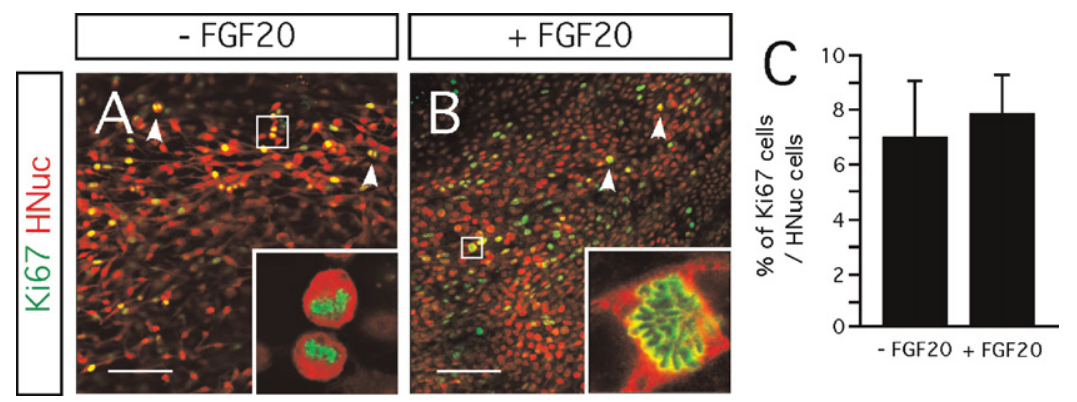

Figure 5. Effect FGF-20 on cell proliferation. (A,B) Representative images of Ki67- and HNuc-positive cells in 3 weeks differentiated hESCs/PA6 co-cultures FGF-20 (A) and +FGF-20 (B). Arrowheads point on cells going through mitosis. (C) Graphic representation of the percentages of Ki67-positive cells among HNucpositive cells in 3 weeks differentiated hESCs/PA6 co-cultures -FGF-20 and +FGF-20. Average \pm SEM. Distance bars: $100 \mu \mathrm{m}$.

decreased from $2.5 \%$ to $1.2 \%$ with the addition of FGF-20 (Figure 4I). Cultures expressed the midbrain dopaminergic markers, PITX3, En1, TH, Msx1, and Aldh1 (Figures 2D-2H), supporting the notion that hESCderived cells were committed to a midbrain dopaminergic phenotype. The percentage of b-III-Tubulin-positive cells in the hESC-derived cultures was about $17 \%$ regardless of whether FGF-20 was present or not (Figure 3 ), indicating that this growth factor did not increase overall neuronal differentiation.

FGF-20 enhances the dopaminergic differentiation of stem cells in vitro (Grothe et al., 2004; Takagi et al., 2005). Thus, higher yields of dopaminergic neurons were obtained when neuronal stem cells overexpressing Nurr1 (Grothe et al., 2004) or monkey ESCs (Takagi et al., 2005) were differentiated in the presence of FGF-20. In concordance to our results, the latter study showed that a combination of bFGF and FGF-20 supported a fivefold increase, from $5 \%$ to $24 \%$, in the percentage of TH-positive neurons (expressed as a proportion of Tuj1positive cells) compared to the condition when both factors were absent (Takagi et al., 2005). The mechanism by which the combination of bFGF and FGF-20 enhances the yield of stem cell-derived dopaminergic neurons still remains to be investigated (Takagi et al., 2005).

Other signaling molecules, such as sonic hedgehog (SHH), FGF-8 (Park et al., 2005), and GDNF (Buytaert-Hoefen et al., 2004), can also increase the number of TH-positive cells derived from hESCs that are co-cultured with PA6 cells. A combination of SHH and FGF-8 increased the percentage of TH-expressing neurons out of the TuJ1-positive cells from $26 \%$ to $41 \%$ (Park et al., 2005). GDNF doubled the number of TH-positive cells. The numbers of TH-positive cells per well in this study were about 934 when GDNF was added and 443 when this neurotrophic factor was not added (Buytaert-Hoefen et al., 2004).

Several neurotrophic factors demonstrate a growth-stimulating effect and increase both the cell body size and the length and branching of neurites of mesencephalic dopaminergic neurons. Those include GDNF (Widmer et al., 2000), BDNF, NT-3, NT-4/5, nerve growth factor (NGF) (Studer et al., 1995; Studer et al., 1996), and TGF-alpha (Alexi and Hefti, 1993). Unlike those factors, FGF-20 neither increased the cell body size nor the length of the neurites of the TH-immunoreactive neurons (Figures 2I and 2J). Instead the effect was limited to enhancing the number of TH-positive neurons.

The neurotrophic activity of FGF-20 on rat mesencephalic dopaminergic neurons is probably mediated by FGFR-1c (Ohmachi et al., 2003). This receptor mediates the signaling of several different FGF molecules, such as FGF-1, -2, -3, -4, -5, -6, and -10 (Eswarakumar et al., 2005). Consequently, it is present on many different cell types. We detected FGFR-1 on PA6 cells, undifferentiated hESCs and hESCs-derived THpositive neurons (Figures 1G-10), indicating that the FGF-20 might act on different cell types in our culture paradigm. Thus, FGF-20 could act directly on the pluripotent hESCs, promoting their differentiation into dopaminergic neurons; on the hESC-derived dopaminergic neurons to increase their survival; and/or indirectly, by acting on the PA6 cells and inducing to produce factors that promote differentiation and survival of dopaminergic neurons. FGF-20 has previously been suggested to have an indirect mode of action on dopaminergic differentiation (Grothe et al., 2004).

FGF-20 has been suggested to activate anti-apoptotic defenses in cultured rat mesencephalic dopaminergic neurons (Murase and McKay, 2006). FGF-20 prevents dopaminergic neurons from dying in cultures lacking serum, or exposed to glutamate- or 6-hydroxydopamine (6OHDA)-induced excitotoxicity, as well as from oxidative stress caused by intracellular dopamine (Murase and McKay, 2006; Ohmachi et al., 2000; Ohmachi et al., 2003). This effect was specific to calbindin-negative cultured dopaminergic neurons, suggesting that it is limited to the A9 substantia nigra dopaminergic neurons and not evident in those derived from the adjacent A10 ventral tegmental area (Murase and McKay, 2006). We observed a significant difference in the number of cells positive for cleaved caspase-3 in FGF-20-supplemented cultures (1.2\%), compared to the untreated cultures $(2.5 \%$, Figures $4 \mathrm{C}, 4 \mathrm{~F}$, and $4 \mathrm{I})$. Furthermore, we also observed lower numbers of cells positive for the apoptotic markers cleaved caspase- 8 and BAX when FGF-20 was added to the cultures (Figures 4A, 4B, 4D, and 4E). Cleaved caspase-8 is involved in initiating the extrinsic pathway, while BAX polymerization mediates mitochondrial cytochrome $c$ release as an early step in the intrinsic pathway (Riedl and Shi, 2004). Therefore, the decreased number of cells positive for cleaved caspase- 8 and BAX in FGF-20 supplemented cultures suggests that this growth factor inhibits apoptosis through both extrinsic and intrinsic pathways. Previously, was shown that FGF-20 treatment results in the phosphorylation phosphoinositide-3 kinase (PI3K) (Murase and McKay, 2006). Phosphorylated PI3K then activates the Akt-dependent antiapoptotic pathway, which involves the inactivation of the proapoptotic protein $B A D$ and consequently the repression of the intrinsic pathway (del Peso et al., 1997). We are not aware of any reported link between the FGF20 signaling and the caspase- 8 activation.

Although the percentage of cells exhibiting cleaved caspase- 3 at the time of fixation, 21 days after starting the co-culture, was small, it has to be emphasized that detection of cleaved caspase-3 is limited to a number of hours before a cell eventually lyses and disappears from the culture. These percentages of cleaved caspase-3-positive cells only indicate that at the time point when we studied cell death, the fraction of cells expressing cleaved caspase- 3 was $2.5 \%$ in control cultures, while in FGF20 treated cultures only $1.2 \%$ of the cells presented cleaved caspase- 3 . Thus, these percentages do not reflect the cells that had died throughout the full culture experiment, which lasted for 21 days. If the rate of cell death is similar over the full 21-day culture period, the addition of FGF-20 results in a $52 \%$ reduction in the cell death (difference between the percentage of cleaved caspase-3 without and with FGF-20 (2.5-1.2 = 1.3) divided by the percentage without FGF-20 $(1.3 / 2.5=52))$. This can amount to a substantial increase in living TH-positive neurons in the FGF- 
20 treated cultures. Most of the cells that are protected from dying by FGF-20 are probably dopaminergic neurons, assuming that FGF-20 preferentially affects this type of neurons as reported previously (Ohmachi et al., 2000; Ohmachi et al., 2003). Expression of this growth factor is specific to the substantia nigra pars compacta in the rat brain (Ohmachi et al., 2000). In addition, the receptor for FGF-20, FGFR1c, is highly expressed by TH-positive neurons in the substantia nigra and is lower in other brain regions (Ohmachi et al., 2003). Moreover, in primary, serumfree, rat mesencephalic cultures, FGF-20 only rescues the TH-expressing cells and does not affect the total number of neurons (Ohmachi et al., 2003). Unfortunately, we were not able to definitively determine if the dying neurons were dopaminergic. The identification of dying dopaminergic neurons in culture cannot be easily done, because dying cells downregulate cytosolic proteins such as TH (Burke, 2004). Therefore, the fact that we did not find cells immunopositive for both TH and cleaved caspase-3, does not clarify the issue.

In conclusion, in the present study we demonstrate that FGF-20 has potent effect on dopaminergic neurons generated from hESCs. This effect could largely be due to specific promotion of cell differentiation toward the dopaminergic phenotype combined with a reduced cell death. The high yield of dopaminergic neurons from $\mathrm{hESC}$ might provide an advantage for neural transplantation in models of Parkinson's disease. For this reason, in our future studies we are interested to see if FGF-20 can improve the yield of hESC-derived TH-positive neurons after grafting. One of the major limitations in the application of hESCs in cell therapy for Parkinson's disease is that only few hESC-derived dopaminergic neurons survive after transplantation into animal models (Ben-Hur et al., 2004; Brederlau et al., 2006; Park et al., 2005; Zeng et al., 2004). We believe that FGF-20 can contribute to obtain large quantities of dopaminergic neurons with substantia nigra phenotype from $\mathrm{hESCs}$, increasing the chances of success for stem cell-based therapy against Parkinson's disease.

\section{CONFLICT OF INTEREST STATEMENT}

The authors declare that the research was conducted in the absence of any commercial or financial relationships that could be construed as a potential conflict of interest.

\section{ACKNOWLEDGMENTS}

The authors thank Ingrid Sandelin and Ingar Nilsson for their excellent technical support and Birgitta Larsson for her help in grant administration. This study was supported by the following grants: United States Army Medical Research Acquisition Activity (USAMRAA, Award No. W81XWH04-1-0366); NeuroFortis (IS, IN); Thorsten och Elsa Segerfalks Stiftelse (JYL); Grants from the Swedish Research Council (PB, JYL); Crafoordska Stiftelsen (JYL, SVA); Swedish Parkinson Foundation (JYL, SVA); Torsten och Ragnar Söderbergs stiftelser (PB); Stiftelsen Olle Engkvist Byggmästare (PB); Konung Gustaf V:s och Drottning Victorias Stiftelse $(\mathrm{PB})$; Swedish Brain Foundation $(\mathrm{PB})$ and Fundação para a Ciência e Tecnologia (ref SFRH/BD/11804/2003 to ASC).

\section{REFERENCES}

Alberi, L., Sgado, P., and Simon, H. H. (2004). Engrailed genes are cell-autonomously required to prevent apoptosis in mesencephalic dopaminergic neurons. Development 131, 3229-3236.

Alexi, T., and Hefti, F. (1993). Trophic actions of transforming growth factor alpha on mesencephalic dopaminergic neurons developing in culture. Neuroscience 55,903 918.

Andersson, E., Tryggvason, U., Deng, Q., Friling, S., Alekseenko, Z., Robert, B., Perlmann, T., and Ericson, J. (2006). Identification of intrinsic determinants of midbrain dopamine neurons. Cell 124, 393-405.

Ben-Hur, T., Idelson, M., Khaner, H., Pera, M., Reinhartz, E., Itzik, A., and Reubinoff, B. E. (2004). Transplantation of human embryonic stem cell-derived neural progenitors improves behavioral deficit in Parkinsonian rats. Stem Cells 22, 1246-1255.

Bjorklund, A., Dunnett, S. B., Brundin, P., Stoessl, A. J., Freed, C. R., Breeze, R. E., Levivier, M., Peschanski, M., Studer, L., and Barker, R. (2003). Neural transplantation for the treatment of Parkinson's disease. Lancet Neurol. 2, 437-445.
Braak, H., Ghebremedhin, E., Rub, U., Bratzke, H., and Del Tredici, K. (2004). Stages in the development of Parkinson's disease-related pathology. Cell Tissue Res. 318, $121-134$.

Brederlau, A., Correia, A. S., Anisimov, S. V., Elmi, M., Paul, G., Roybon, L., Morizane, A., Bergquist, F., Riebe, I., and Nannmark, U. et al., (2006). Transplantation of human embryonic stem cell-derived cells to a rat model of Parkinson's disease: effect of in vitro differentiation on graft survival and teratoma formation. Stem Cells 24, 14331440 .

Burke, R. E. (2004). Ontogenic cell death in the nigrostriatal system. Cell Tissue Res. 318 , 63-72.

Buytaert-Hoefen, K. A., Alvarez, E., and Freed, C. R. (2004). Generation of tyrosine hydroxylase positive neurons from human embryonic stem cells after coculture with cellular substrates and exposure to GDNF. Stem Cells 22, 669-674.

del Peso, L., Gonzalez-Garcia, M., Page, C., Herrera, R., and Nunez, G. (1997). Interleukin-3-induced phosphorylation of BAD through the protein kinase Akt. Science 278, 687-689.

Eswarakumar, V. P., Lax, I., and Schlessinger, J. (2005). Cellular signaling by fibroblast growth factor receptors. Cytokine Growth Factor Rev. 16, 139-149.

Freeman, T. F., and Brundin, P. (2006). Important aspects of surgical methodology for transplantation in Parkinson's disease. In Restorative Therapies in Parkinson's Disease, P. Brundin and W. Olanow, eds. (New York, NY, USA, Springer Science + Business Media, LLC), pp. 131-165.

Galter, D., Buervenich, S., Carmine, A., Anvret, M., and Olson, L. (2003). ALDH1 mRNA: presence in human dopamine neurons and decreases in substantia nigra in Parkinson's disease and in the ventral tegmental area in schizophrenia. Neurobiol. Dis. 14, 637-647.

Grothe, C., Timmer, M., Scholz, T., Winkler, C., Nikkhah, G., Claus, P., Itoh, N., and Arenas, E. (2004). Fibroblast growth factor-20 promotes the differentiation of Nurr1overexpressing neural stem cells into tyrosine hydroxylase-positive neurons. Neurobiol. Dis. 17, 163-170.

Hori, Y., Gu, X., Xie, X., and Kim, S. K. (2005). Differentiation of insulin-producing cells from human neural progenitor cells. PLoS Med. 2, e103.

lacovitti, L., Donaldson, A. E., Marshall, C. E., Suon, S., and Yang, M. (2007). A protocol for the differentiation of human embryonic stem cells into dopaminergic neurons using only chemically defined human additives: studies in vitro and in vivo. Brain Res. 1127, 19-25.

Jorgensen, J. R., Juliusson, B., Henriksen, K. F., Hansen, C., Knudsen, S., Petersen, T. N., Blom, N., Seiger, A., and Wahlberg, L. U. (2006). Identification of novel genes regulated in the developing human ventral mesencephalon. Exp. Neurol. 198, 427-437.

Kawasaki, H., Mizuseki, K., Nishikawa, S., Kaneko, S., Kuwana, Y., Nakanishi, S. Nishikawa, S. I., and Sasai, Y. (2000). Induction of midbrain dopaminergic neurons from ES cells by stromal cell-derived inducing activity. Neuron 28, 31-40.

Kukekov, V. G., Laywell, E. D., Suslov, O., Davies, K., Scheffler, B., Thomas, L. B., O'Brien, T. F., Kusakabe, M., and Steindler, D. A. (1999). Multipotent stem/progenitor cells with similar properties arise from two neurogenic regions of adult human brain. Exp. Neurol. 156, 333-344.

Morizane, A., Takahashi, J., Takagi, Y., Sasai, Y., and Hashimoto, N. (2002). Optimal conditions for in vivo induction of dopaminergic neurons from embryonic stem cells through stromal cell-derived inducing activity. J. Neurosci. Res. 69, 934-939.

Murase, S., and McKay, R. D. (2006). A specific survival response in dopamine neurons at most risk in Parkinson's disease. J. Neurosci. 26, 9750-9760.

Nirenberg, M. J., Chan, J., Liu, Y., Edwards, R. H., and Pickel, V. M. (1996). Ultrastructural localization of the vesicular monoamine transporter-2 in midbrain dopaminergic neurons: potential sites for somatodendritic storage and release of dopamine. $\mathrm{J}$. Neurosci. 16, 4135-4145.

Nunes, I., Tovmasian, L. T., Silva, R. M., Burke, R. E., and Goff, S. P. (2003). Pitx3 is required for development of substantia nigra dopaminergic neurons. Proc. Natt. Acad. Sci. U S A 100, 4245-4250.

Ohmachi, S., Watanabe, Y., Mikami, T., Kusu, N., Ibi, T., Akaike, A., and Itoh, N. (2000). FGF-20, a novel neurotrophic factor, preferentially expressed in the substantia nigra pars compacta of rat brain. Biochem. Biophys. Res. Commun. 277, 355-360.

Ohmachi, S., Mikami, T., Konishi, M., Miyake, A., and Itoh, N. (2003). Preferential neurotrophic activity of fibroblast growth factor-20 for dopaminergic neurons through fibroblast growth factor receptor-1c. J. Neurosci. Res. 72, 436-443.

Park, S., Lee, K. S., Lee, Y. J., Shin, H. A., Cho, H. Y., Wang, K. C., Kim, Y. S., Lee, H. T., Chung, K. S., Kim, E. Y., and Lim, J. (2004). Generation of dopaminergic neurons in vitro from human embryonic stem cells treated with neurotrophic factors. Neurosci. Lett. 359, 99-103.

Park, C. H., Minn, Y. K., Lee, J. Y., Choi, D. H., Chang, M. Y., Shim, J. W., Ko, J. Y., Koh, H. C., Kang, M. J., and Kang, J. S. et al., (2005). In vitro and in vivo analyses of human embryonic stem cell-derived dopamine neurons. J. Neurochem. 92, 1265-1276.

Perrier, A. L., Tabar, V., Barberi, T., Rubio, M. E., Bruses, J., Topf, N., Harrison, N. L., and Studer, L. (2004). Derivation of midbrain dopamine neurons from human embryonic stem cells. Proc. Natl. Acad. Sci. U S A 101, 12543-12548.

Riedl, S. J., and Shi, Y. (2004). Molecular mechanisms of caspase regulation during apoptosis. Nat. Rev. Mol. Cell Biol. 5, 897-907.

Ronn, L. C., Ralets, I., Hartz, B. P., Bech, M., Berezin, A., Berezin, V., Moller, A., and Bock, E. (2000). A simple procedure for quantification of neurite outgrowth based on stereological principles. J. Neurosci. Methods 100, 25-32.

Roy, N. S., Cleren, C., Singh, S. K., Yang, L., Beal, M. F., and Goldman, S. A. (2006). Functional engraftment of human ES cell-derived dopaminergic neurons enriched by coculture with telomerase-immortalized midbrain astrocytes. Nat. Med. 12, 12591268 . 
Schulz, T. C., Noggle, S. A., Palmarini, G. M., Weiler, D. A., Lyons, I. G., Pensa, K. A Meedeniya, A. C., Davidson, B. P., Lambert, N. A., and Condie, B. G. (2004) Differentiation of human embryonic stem cells to dopaminergic neurons in serumfree suspension culture. Stem Cells 22, 1218-1238.

Studer, L., Spenger, C., Seiler, R. W., Altar, C. A., Lindsay, R. M., and Hyman, C. (1995) Comparison of the effects of the neurotrophins on the morphological structure of dopaminergic neurons in cultures of rat substantia nigra. Eur. J. Neurosci. 7, 223233.

Studer, L., Spenger, C., Seiler, R. W., Othberg, A., Lindvall, O., and Odin, P. (1996). Effects of brain-derived neurotrophic factor on neuronal structure of dopaminergic neurons in dissociated cultures of human fetal mesencephalon. Exp. Brain Res. 108, 328336.

Takagi, Y., Takahashi, J., Saiki, H., Morizane, A., Hayashi, T., Kishi, Y., Fukuda, H., Okamoto, Y. Koyanagi, M., and Ideguchi, M. et al., (2005). Dopaminergic neurons generated from monkey embryonic stem cells function in a Parkinson primate model. J. Clin. Invest. 115, 102-109.
Takahashi, J. (2007). Stem cell therapy for Parkinson's disease. Expert Rev. Neurother 7, 667-675.

Widmer, H. R., Schaller, B., Meyer, M., and Seiler, R. W. (2000). Glial cell line-derived neurotrophic factor stimulates the morphological differentiation of cultured ventral mesencephalic calbindin- and calretinin-expressing neurons. Exp. Neurol. 164, 7181.

Yan, Y, Yang, D., Zarnowska, E. D., Du, Z Werbel, B, Valliere, C, Pearce, R. A Thomson, J. A., and Zhang, S. C. (2005). Directed differentiation of dopaminergic neuronal subtypes from human embryonic stem cells. Stem Cells 23, 781790.

Yu, H., Fang, D., Kumar, S. M., Li, L., Nguyen, T. K., Acs, G., Herlyn, M., and Xu, X. (2006). Isolation of a novel population of multipotent adult stem cells from human hair follicles. Am. J. Pathol. 168, 1879-1888.

Zeng, X, Cai, J., Chen, J., Luo, Y Y, You, Z B., Fotter, E., Wang, Y, Harvey, B., Miura, T, and Backman, C. et al., (2004). Dopaminergic differentiation of human embryonic stem cells. Stem Cells 22, 925-940. 